\title{
Solid Acids for the Reaction of Bioderived Alcohols into Ethers for Fuel Applications
}

\author{
Federica Zaccheria *, Nicola Scotti and Nicoletta Ravasio \\ CNR, Istituto di Scienze e Tecnologie Molecolari, Via C. Golgi 19, 20133 Milano, Italy; n.scotti@istm.cnr.it (N.S.); \\ n.ravasio@istm.cnr.it (N.R.) \\ * Correspondence: f.zaccheria@istm.cnr.it; Tel.: +39-02-50314384
}

Received: 19 December 2018; Accepted: 1 February 2019; Published: 12 February 2019

check for updates

\begin{abstract}
The use of solids acids in the synthesis of ethers suitable to be used as fuels or fuel additives were reviewed in a critical way. In particular, the role of Brønsted and Lewis acid sites was highlighted to focus on the pivotal role of the acidity nature on the product distribution. Particular emphasis is given to the recently proposed ethers prepared starting from furfural and 5-hydroxymethyl furfural. Thus, they are very promising products that can be derived from lignocellulosic biomass and bioalcohols and possess very interesting chemical and physical properties for their use in the diesel sector.
\end{abstract}

Keywords: ethers; furanics; zeolites; solid acids; Brønsted sites; Lewis sites

\section{Introduction}

Oxygenated fuels, such as alcohols and ethers, represent an important alternative to conventional non-oxygenated ones. In fact, the use of oxygen containing molecules in internal combustion engines provides several advantages in terms of environmental impact, namely in reducing greenhouse gas emissions (GHG), due to the low content of pollutants, like sulfur, and to complete combustion reducing formation of particulate. [1,2].

Their use varies from the role of additives in gasoline to the formulation in diesel blends depending on their structure (Table 1).

Ethers, such as methyl tert butyl ether (MTBE), have been used as an octane booster instead of tetraethyl lead and to decrease engine emissions. For these reasons, MTBE use has seen a speedy growth until the end of the 1990s and after, while in the past decade, the worldwide market underwent significant changes because of the ban in the US and Canada [3]. Thus, MTBE is toxic, volatile, and flammable and its use entails several concerns for human and water protection [4].

Dimethylether (DME), already in use since 1867 as an anesthetic agent, has been used in diesel engines starting from 1986 and its production is foreseen to gradually increase, particularly on the wave of bio-DME synthesis [5]. Also, ethyl tert-butyl ether (ETBE) and tert-amyl methyl ether (TAME) have been successfully introduced to replace tetraethyl lead (i.e., a toxic pollutant) in gasoline.

The strategic role of oxygenated components in the fuel market is witnessed by the presence of several networks and associations born to promote the responsible diffusion of oxygenated fuels, both alcohols and ether ones. Examples of this approach are the European Fuel Oxygenates Association (EFOA) and the International DME Association (IDA). 
Table 1. Most widespread ethers for fuel applications.

\begin{tabular}{|c|c|c|c|}
\hline Ether & Structure & Bio-moiety & Fuel sector \\
\hline $\begin{array}{l}\text { Dimethyl ether } \\
\text { DME }\end{array}$ & & Methanol & $\begin{array}{l}\text { Gasoline and diesel } \\
\text { blend }\end{array}$ \\
\hline $\begin{array}{l}\text { Diethyl ether } \\
\text { DEE }\end{array}$ & & Ethanol & $\begin{array}{c}\text { Gasoline and diesel } \\
\text { blend }\end{array}$ \\
\hline $\begin{array}{l}\text { Dibutyl ether } \\
\text { DBE }\end{array}$ & & Butanol & $\begin{array}{c}\text { Gasoline and diesel } \\
\text { blend }\end{array}$ \\
\hline $\begin{array}{c}\text { Methyl tert-butyl ether } \\
\text { MTBE }\end{array}$ & & methanol & $\begin{array}{l}\text { Octane booster for } \\
\text { gasoline }\end{array}$ \\
\hline $\begin{array}{l}\text { Ethyl tert-butyl ether } \\
\text { ETBE }\end{array}$ & & ethanol & $\begin{array}{l}\text { Octane booster for } \\
\text { gasoline }\end{array}$ \\
\hline $\begin{array}{c}\text { Tert-amyl methylether } \\
\text { TAME }\end{array}$ & & nethanol & $\begin{array}{l}\text { Octane booster for } \\
\text { gasoline }\end{array}$ \\
\hline $\begin{array}{c}\text { Tert-amyl ethyl ether } \\
\text { TAEE }\end{array}$ & & ethanol & $\begin{array}{l}\text { Octane booster for } \\
\text { gasoline }\end{array}$ \\
\hline $\begin{array}{c}\text { di- and tri-tert-butyl glycerol } \\
\text { ether } \\
\text { DTBG and TTBG }\end{array}$ & & Glycerol & Diesel additives \\
\hline $\begin{array}{c}\text { di- and tri-ethyl glycerol } \\
\text { ether } \\
\text { DEG and TEG }\end{array}$ & & Glycerol ethanol & Diesel additives \\
\hline Alkoxymethyl furan & & Furfural alcohol & Diesel blend \\
\hline Alkoxymethyl furfural & & HMF alcohol & Diesel blend \\
\hline 2,5-bis(alkoxymethyl)furan & & HMF alcohol & Diesel blend \\
\hline
\end{tabular}


The possibility to use bioalcohols has certainly played a major role in the development and diffusion of ethers in the fuel sector. In particular, ethanol and butanol can be obtained from fermentation processes starting form a wide variety of lignocellulosic biomass (Figure 1).

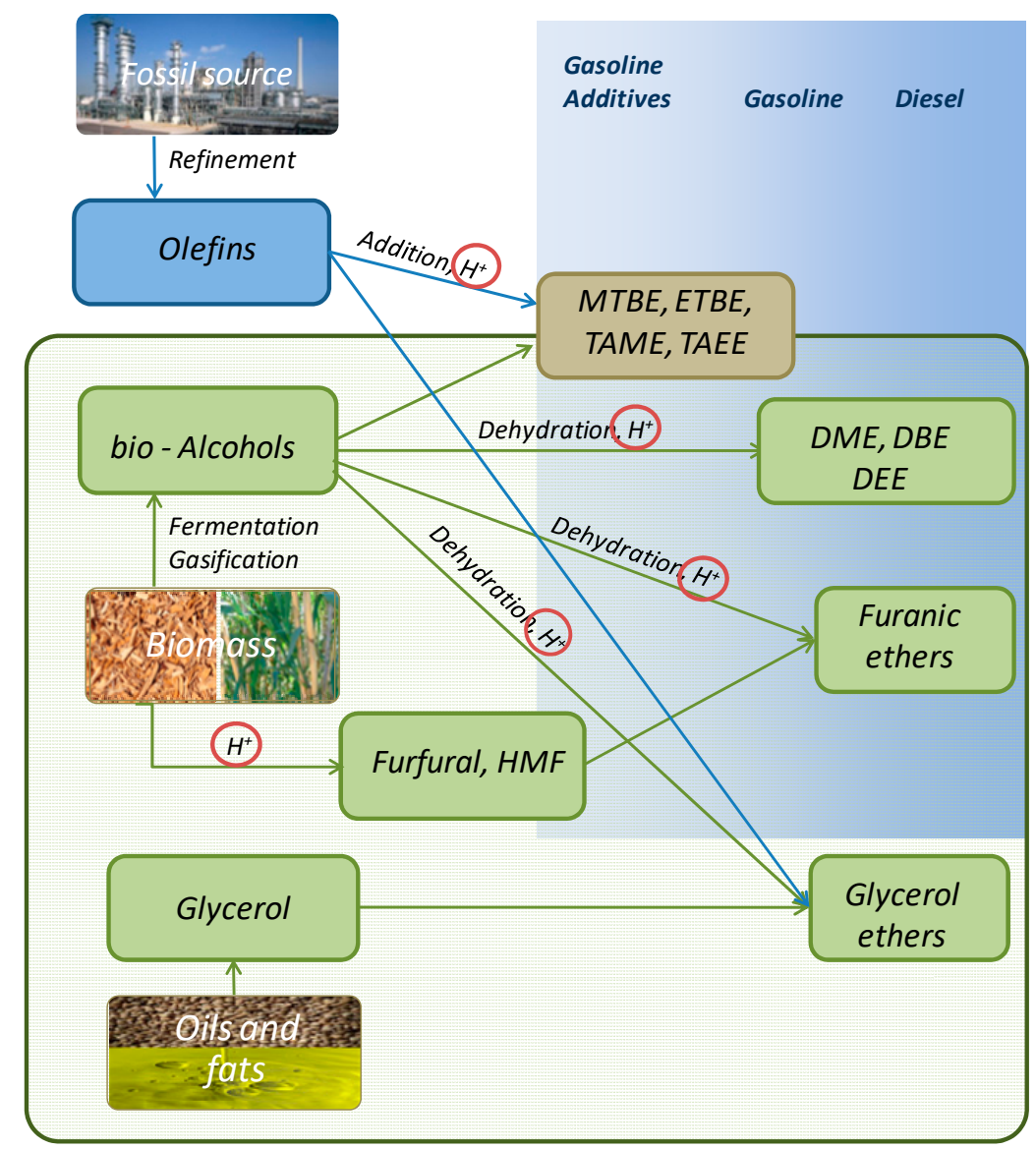

Figure 1. Major routes to ethers for fuel blending.

The production of bioethanol has seen an enormous increase in recent years, reaching a world production of more than 27 thousands of million gallons in 2017 [6]. The ethanol production process is industrially mature and it can be produced from any materials containing sugar molecules. Fermentation processes applied to non-edible feedstock sourced from agriculture and forestry wastes strongly increase the advantages obtained with its use [7].

The industrial production of biobutanol relies on the improvement of the over 100-year old ABE (acetone-butanol-ethanol) process and it is now an economically viable and competitive product with a global market expected to reach $17.78 \mathrm{M}$ USD by 2022 [8].

An additional source derives from the biodiesel industry that provides glycerol as the main by-product of the transesterification reaction of triglycerides with methanol or ethanol and glycerol availability is foreseen to reach 4 billion gallons by 2020 [9]. The use of a polyalcohol, such as glycerol, allows one to obtain branched ethers that possess very interesting features as diesel additives due to their excellent combustion properties, good blending ability, and high cetane number [10].

More recently, the preparation of ethers derived from biomass platform molecules, such as hydroxyl methyl furfural (HMF) and furfural, have also gained great attention due to their interesting properties in the diesel sector [11].

Synthetic strategies for the C-O-C bond formation are traditionally based on the reaction of an alkoxide with a chloride intermediate, according to the Williamson reaction. On the other hand, the use of alternative routes and of heterogeneous catalysts allows the avoidance of wastes and inconvenient intermediates, which is highly desirable. 
Two main alternative strategies have been used for the preparation of ethers to be used in fuels and fuel blending, namely the addition of an alcohol to a C-C double bond, as it is the case of MTBE and TAME, or the dehydration of two alcohol molecules, which is the pathway followed for DME, DE, and furanics (Scheme 1).<smiles>[R]C([R])=C</smiles>
$+\mathrm{R} " \mathrm{OH}$

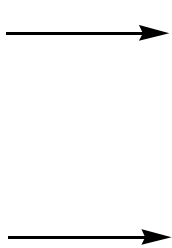<smiles>[R]OC([R])([R])C</smiles>

ROR'
Addition

\section{Dehydration}

Scheme 1. General ether synthesis used for common fuel ethers.

Both synthetic ways are based on the use of acidic catalysts that are able to promote the activation of the double bond towards alcohol addition, making it more electrophilic, or the dehydration of alcohols. The use of solid acids, formerly covering a pivotal role in traditional refinery processes, has seen a rejuvenating moment and has received much attention due to its application to biomass deconstruction and transformation [12]. The study and design of innovative and performing heterogeneous acid systems has therefore seen much attention and advancement.

This review mainly intends to highlight the most peculiar aspects related with the use of heterogeneous catalysts and particularly acid solid catalysts in the synthesis of this main class of ethers employed in fuels, taking as examples MTBE and DME and giving a particular emphasis on furanic ethers due to their most recent development. MTBE, DME, and furanics are chosen as examples to identify and highlight the different needs and possibilities in tuning the catalysts' acidity to obtain both high activity and selectivity in the desired products depending on the critical points of the different syntheses.

\section{The Use of Solid Acids in MTBE Synthesis}

The industrial synthesis of MTBE is based on the addition of methanol to isobutene. As already mentioned, its use has seen a dramatic decrease due to its impact on drinking water contamination. The United States environmental protection agency (USEPA) has in fact categorized MTBE as a possible carcinogenic agent, thus preventing its use as a gasoline additive since May 2006 [13]. Therefore, the USA, Canada, Japan, and Western Europe shifted to ETBE, ethanol, or TAME. On the contrary, Eastern Europe and Asia Pacific countries built new MTBE capacities as its demand increased, depending on the boost in gasoline consumption and requirements for cleaner fuels. This scenario makes MTBE still an important industrial product, but susceptible to important variations. Consequently, the research activity on MTBE synthesis has seen a drastic break in the last decade, but the main conclusions drawn about the use of heterogeneous catalysts can give important prompts in understanding the acidity features of solid systems employed in this kind of reaction, used also for TAME and TAEE.

The traditional industrial process is based on a liquid phase reaction of methanol with isobutene (molar feed ratio 1:1) at temperatures in the range of $50-100{ }^{\circ} \mathrm{C}$ promoted by an ion exchange resin, namely Amberlyst-15 [14].

On the other hand, several studies have focused on the use of zeolites due to their higher thermal stability and easier industrial application with respect to sulphonic resins as well as their higher selectivity despite lower activity.

The reaction is an acid catalyzed process that can proceed via preliminary protonation of isobutene, followed by the addition of methanol. Alternatively, a mechanism based on the formation of a methoxonium ion acting as proton donor could take place [15]. 
In any case, a typically Brønsted catalyzed reaction is involved and one of the main parameters that is recognized to be crucial for the catalyst activity is the number of acid sites, that is in fact the strong point of Amberlyst- 15 as compared to zeolites. Thus, the resin has a Brønsted acid site concentration of $4.8 \mathrm{mmol} / \mathrm{g}$ versus 1.3 and 2.2 observed in H-ZSM- 5 and HY zeolites, respectively [11].

The main attempts in obtaining efficient zeolites for the methanol/isobutene reaction have therefore been directed to the enhancement of the acidic properties.

One of the methods explored was the dealumination process [16], leading to the removal of some structural $\mathrm{Al}$ and resulting in a decrease in concentration sites, but an increase in acid strength. Indeed, dealumination strongly improved the performances of zeolites in the synthesis of MTBE [17], where a monotonic increase in TOF (defined as the ratio between the reaction rate and the concentration of Brønsted acid sites) was observed with the (extra lattice $\mathrm{Al}$ )/(lattice $\mathrm{Al}$ ) ratio. Interactions between the extra-lattice $\mathrm{Al}$ obtained by dealumination and the acid sites connected with the lattice $\mathrm{Al}$ appeared to cause acid strength enhancement, in turn responsible for the increase in MTBE formation.

The formation of extra-lattice $\mathrm{Al}$ can also be obtained by means of other modifications, such as treatment with strong electron-withdrawing compounds, such as triflic acid and ammonium fluoride $[18,19]$.

On the other hand, other authors ascribe the increase of activity in MTBE synthesis derived from dealumination to the contribution of the external surface area and not to the extra-framework aluminum species [20]. In particular, dealuminated H-beta is as active as Amberlyst-15 when it has $\mathrm{Si} / \mathrm{Al}$ ratios from 13 to 35, and the MTBE yield depends on the external surface area: The higher the area, the higher the yield.

Some studies were also reported on the synthesis of MTBE starting from methanol and tert-butanol via dehydration under gas phase conditions by using $\mathrm{H}$-zeolites. The comparison of various zeolites allows observations of an activity comparable to the one observed with Amberlyst-15, even when Lewis acid sites are the main ones on the catalyst surface, as in the case of $\mathrm{H} \beta$ [21]. Other catalytic systems proposed for this application are sulphated $\mathrm{ZrO}_{2}$ or supported heteropolyacids [22].

In all cases, the understanding of the relationship between the strength of acidity and the number of acidic sites represents the main route to optimize the obtained performances and to design a catalyst potentially more suitable for industrial needs.

A very similar approach is taken for the synthesis of ETBE, which has become a popular alternative to MTBE, possessing superior properties due to its higher octane rating, higher boiling point, lower flash point, lower volatility, and water solubility. The ETBE production capacity increased from 2 million tons to 4 million tons from 2005 to 2007 and it is mainly used as a fuel additive in several European countries, including France, the Netherlands, Germany, Spain, and Belgium [23].

\section{The Use of Solid Acids in DME synthesis}

DME has applications in both the chemical and fuel market, and its demand has seen rapid growth from a global production of $30 \mathrm{kt} /$ year in 2000 to $11.5 \mathrm{Mt} /$ year in 2012, with the total cost of DME world production foreseen to reach US $\$ 9.7$ billion by 2020 [24].

Besides its use in aerosols, varnishes, and pesticides manufacturing, the most important industrial value of dimethyl ether is associated with the global fuel market. Thus, its physical properties make DME similar to liquefied petroleum gas (LPG). Thus, its heat capacity is somewhat lower than that of LPG, but it is easier to liquefy when decompressed and it does not produce a green-house effect. Moreover, DME, as opposed to LPG, has a high cetane number (55-60).

Dimethyl ether is the simplest one among the alkylic ethers and it can be obtained by methanol vapor-phase dehydration via an acid catalyzed reaction. On the other hand, the most recent developments aim to achieve direct synthesis of DME from syngas to obtain a strategic process intensification, considering that methanol itself is produced starting from $\mathrm{CO}+\mathrm{H}_{2}$. A step forward is also desirable in using $\mathrm{CO}_{2}$-containing syngas (Scheme 2) [25]. 
Bifunctional or hybrid catalyst

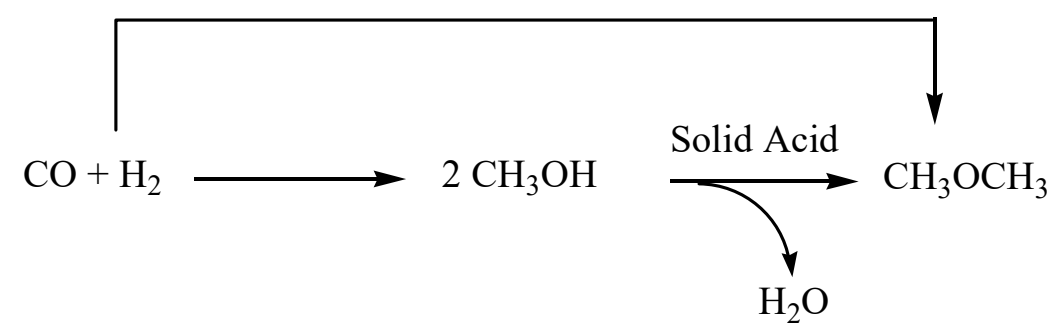

Scheme 2. Synthesis of DME from methanol or directly from syngas.

The main results obtained in the two possible ways are summarized in a review by Sun et al. [26] and the importance of the nature and density of acidic sites in methanol dehydration is emphasized in a very clear description.

In this scenario, two main classes of catalysts are considered, the $\gamma-\mathrm{Al}_{2} \mathrm{O}_{3}$ systems and acidic zeolites. In both cases, the critical point is the maximization of DME's selectivity with respect to the main byproducts, which are methane and coke deposits.

Alumina is basically a good choice due to its high selectivity, low cost, and high resistance and lifetime, and the mechanism in alcohol dehydration with respect to the structure and acidity has been largely studied $[27,28]$.

The activity in methanol dehydration is observed to increase by increasing the acid site density, in turn, depending on the structure type of the alumina, as evidenced in a study based on the comparison of $\gamma-\mathrm{Al}_{2} \mathrm{O}_{3}$ and $\eta-\mathrm{Al}_{2} \mathrm{O}_{3}$ catalysts respectively prepared from boehmite and bayerite via calcination at various temperatures [29].

In an analogous way, a proper modification of $\gamma-\mathrm{Al}_{2} \mathrm{O}_{3}$ with a $\chi-\mathrm{Al}_{2} \mathrm{O}_{3}$ leads to an increase in the acid site density, which allows an increase of the yield in methanol from $50 \%$ to $86 \%$ [30].

Moving from $\mathrm{Al}_{2} \mathrm{O}_{3}$ catalysts to zeolites leads to an increase in activity, due to the higher resistance to water, at the expense of selectivity. In fact, on the one hand, it was shown that generally, the stronger the acid sites, the more active the catalysts. However, when Brønsted sites are involved, their strength and reaction temperature should be controlled to avoid hydrocarbons' formation. [31] Thus, the dehydration reaction is carried out under quite severe conditions, namely temperatures around $250^{\circ} \mathrm{C}$, and several zeolite modifications have been proposed to limit the formation of coke and hydrocarbons.

One of the ways proposed is based on $\mathrm{Na}^{+}$modification of zeolite frameworks [32]. The authors tested a series of zeolites impregnated with increasing amounts of $\mathrm{Na}$, resulting in systems with a reduced total amount of acidic sites and a different distribution of the acidity strength. In particular, the higher the Na content, the lower the density of strong sites and the higher the density of weak sites.

The modification of HZSM- 5 with $80 \%$ mol of Na results in a significant increase in DME yield, particularly when working at $320^{\circ} \mathrm{C}$, which is an important point in the design of a catalyst that is able to promote the reaction starting from syngas, thus requiring high temperatures to be performed.

The beneficial effect of increasing the density of moderate acidic sites was also observed by modifying zeolite $\mathrm{Y}$ with $\mathrm{La}, \mathrm{Ce}$, and $\mathrm{Pr}$ via ion-exchange [33].

The particular case of methanol dehydration into DME identifies the great importance of the acidic sites' strength, regardless of their Lewis or Brønsted nature [32], to make the catalytic system more selective and more resistant under the reaction conditions used. In the case of DME, this aspect is even more important when planning the bifunctional process starting from $\mathrm{CO}+\mathrm{H}_{2}$, requiring temperatures over $300{ }^{\circ} \mathrm{C}$ and a metal based system that is able to promote methanol synthesis.

\section{The Use of Solid Acid in Glycerol Ethers Synthesis}

Glycerol ethers have received great attention due to both its use as a starting material derived from the biodiesel industry and the possibility of obtaining a wide variety of products with different 
industrial applications and economic value. Mono- and di- glycerol ethers in fact find application in several industrial sectors, ranging from the cosmetics to pharmaceuticals, as well as to detergency, inks, polymers, and materials. The possibility to vary the carbon chain linked to the glyceril polar moiety allows the design of a great variety of products that possess tuned properties in terms of hydrophilicity and hydrophobicity [34].

On the other hand, the peculiar structure of glycerol, possessing three-OH groups, offers several possibilities in terms of products and physical behavior, while also raising selectivity issues. The higher ethers with short alcohols, namely di- and tri- derivatives (DAGEs and TAGEs), find a direct application in diesel and biodiesel formulation by virtue of their water insolubility, while the higher polar and hydrophilic mono-ethers (MAGEs) are interesting intermediates for the production of chemicals, such as dioxolanes, in turn studied as fuel components as well (Scheme 3) [35,36].

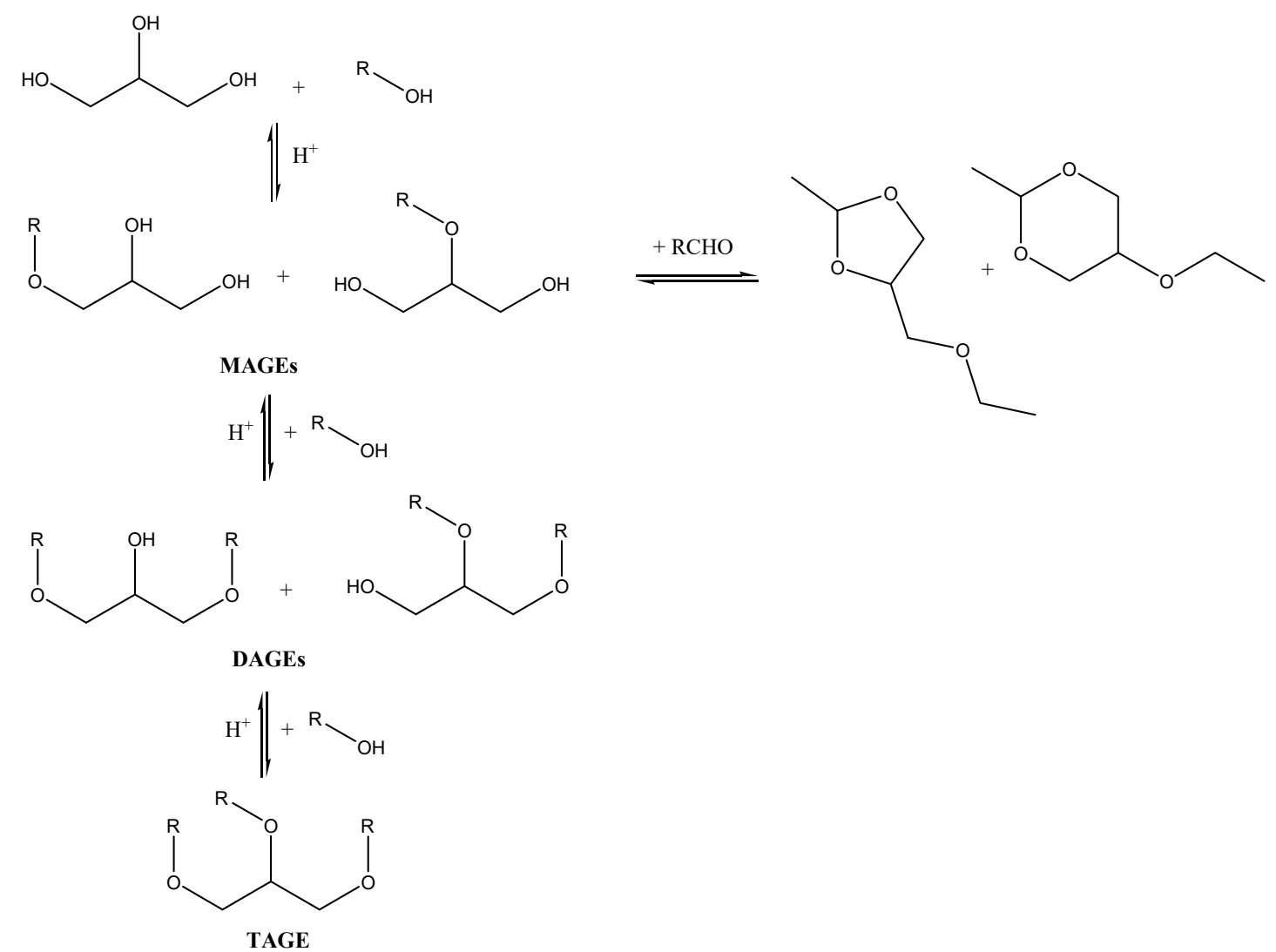

Scheme 3. Etherification of glycerol with alcohol to MAGEs, DAGEs, and TAGE or dioxolanes.

Also, in this case, the strategies for the preparation of ethers are based on the two main routes of addition of the -OH group to alkene or the dehydration of two alcohols.

Much work has been carried out on tert-butyl glycerol ethers, which are obtained by addition of glycerol to isobutylene or by dehydration with tert-butanol (TBA).

The use of isobutylene as an alkylating agent in heterogeneously catalyzed reactions was explored by using ion-exchange resins and zeolites [37-39].

The method of the addition of isobutene was the first attempted one, also based on the examples of MTBE and TAME, but it has technological problems related to the need of using a solvent for glycerol and the drawbacks of handling a three-phase system. On the contrary, the dehydration approach, which exploits the use of tert-butyl alcohol, allows the use of solid-liquid conditions and the use of the alcohol as both the solvent and the reactant. 
Protonic acids are mainly explored and are successful for the etherification of glycerol with tert-butanol, with ionic resins, acidic clays, and sulfonic functionalized materials as the main performing ones.

A study reported by Frusteri et al. [40] showed the importance of the acid sites' accessibility, as it was found when using Amberlyst-15 possessing not only a high acid site density $\left(4.70 \mathrm{mmol}_{\mathrm{H}+} / \mathrm{g}\right)$, but also an average pore diameter of $300 \AA$.

The need to remove water formed during the reaction is one of the most critical points limiting etherification to di- and tri-ethers. In fact, water separation not only shifts the equilibrium, but also limits the competition with tert-butanol and glycerol on the active site adsorption.

A great improvement in this regard is reported when using sulfonated hybrid silicas $\left(\mathrm{S}_{\mathrm{x}} \mathrm{TS}_{100-\mathrm{x}} \mathrm{O}\right)$ [41]. This kind of sulfonated silica gave a $74 \%$ conversion of glycerol with an $18 \%$ yield in di- and tri-ethers (reaching $98 \%$ and $28 \%$ after $24 \mathrm{~h}$ ) at $75{ }^{\circ} \mathrm{C}$ versus a $51 \%$ conversion obtained with A15 under the same conditions. The authors ascribe these results mainly to the hydrophilicity of the surface. The presence of silanol groups on the hybrid silica precludes the inhibition effect of water and, consequently, the conversion increases with time without reaching a maximum, as observed in the case of resins.

An even higher yield in di-tert-butyl glycerol ethers of up to $36 \%$ was obtained with sulfonic acid functionalized mesoporous polymer [42].

Acidic clays, and in particular montmorillonite $\mathrm{KSF} / \mathrm{O}$, require high reaction temperatures, but this allows the obtainment of up to $33 \%$ of di-ethers [43].

On the other hand, isobutylene, C4 fraction, and tert-butanol are obtained from fossil sources, whilst the use of ethanol or butanol would grant a fully bioderived material. The main problem related with the use of shorter alcohols is their lower reactivity as alkylating agents due to the lower stability of the carbocation formed. Therefore, high temperatures are usually requested and, consequently, there are significant limitations in the catalyst choice. In particular, the use of acid ion-exchange resins successfully employed for the etherification with tert-butanol must be avoided due to their poor thermostability, thus making zeolites and modified silicas the most studied systems for this application.

An early paper by the group of Fajula [44] reported on the comparison of sulfonic-acid grafted silicas, zeolites, and acidic resins for the preparation of MAGEs with ethanol, identifying the fundamental role of the hydrophobic/hydrophilic character of the catalyst besides the acidic properties. All the catalysts tested were strongly influenced by the surface polarity.

In fact, within the resins tested, the comparison between Amberlyst and Nafion identified the good activity of the first one compared to the inactivity of the second, while no differences were observed in the side etherification of ethanol to dimethylether, occurring by the high concentration of ethanol used as the solvent. This evidence shows that both catalysts promote etherification of ethanol thanks to their acidity, but the hydrophobic character of the Nafion resin prevents the adsorption of the highly polar and hydrophilic glycerol, thus not allowing the formation of MAGEs. On the contrary, Amberlyst gives up to a $52 \%$ conversion of glycerol with a $90 \%$ selectivity to MAGEs even at $150{ }^{\circ} \mathrm{C}$ (Table 2, entries 1 and 2).

Very similar conclusions can be drawn from the experiments carried out with zeolites. For these systems, the authors found a diagnostic correlation between the activity of different zeolites and their aluminum content, in turn influencing the surface polarity. In fact, high aluminum contents generate a high acidic sites density and a high surface polarity. Maximum activity was observed for $\mathrm{Si} / \mathrm{Al}$ $=25$, representing the best tradeoff between the acidity and surface polarity: A lower aluminum content entails a lower acidity and an $\mathrm{Al} / \mathrm{Si}$ ratio that is too high forces the process to be limited by the hydrophilic character of the catalyst.

The good performances of $\mathrm{H}$-Bea with $\mathrm{Si} / \mathrm{Al}=25$ were also underlined in a study aimed to maximize the content in di- and tri-ethers [45]. 
Table 2. Selected examples of the etherification reaction of glycerol and ethanol.

\begin{tabular}{|c|c|c|c|c|c|c|c|}
\hline Entry & Catalyst & Alcohol & $\mathrm{T}\left({ }^{\circ} \mathrm{C}\right)$ & Product & $\begin{array}{c}\text { Conversion } \\
(\%)\end{array}$ & $\begin{array}{l}\text { Selectivity } \\
(\%)^{a}\end{array}$ & Ref \\
\hline 1 & $\begin{array}{l}\text { Amberlyst } \\
\text { A35 }\end{array}$ & ethanol & 150 & $\begin{array}{l}\text { Monoethyl } \\
\text { glycerol ether }\end{array}$ & 52 & $90(10)$ & [44] \\
\hline 2 & BEA 25 & ethanol & 200 & $\begin{array}{l}\text { Monoethyl } \\
\text { glycerol ether }\end{array}$ & 57 & $75(25)$ & [44] \\
\hline 3 & Amberlyst-15 & ethanol & 180 & - & 96 & $65(19 ; 6)$ & [46] \\
\hline 4 & H-Beta & ethanol & 180 & - & 92 & $71(17 ; 12)$ & [46] \\
\hline 5 & Ar-SBA-15 & ethanol & 200 & $\begin{array}{l}\text { Monoethyl } \\
\text { glycerol ether }\end{array}$ & 73 & $54(14)$ & [47] \\
\hline 6 & $\begin{array}{c}\mathrm{H}_{3} \mathrm{PW}_{12} \mathrm{O}_{40} \\
(\mathrm{HPW})\end{array}$ & ethanol & 160 & $\begin{array}{l}\text { Monoethyl } \\
\text { glycerol ether }\end{array}$ & 97 & $62(28 ; 10)$ & [48] \\
\hline 7 & $\mathrm{HPW} / \mathrm{SiO}_{2}$ & ethanol & 160 & $\begin{array}{l}\text { Monoethyl } \\
\text { glycerol ether }\end{array}$ & 91 & $67(23 ; 9)$ & [48] \\
\hline
\end{tabular}

a Selectivity to DAGE; TAGE in brackets.

Comparable performances of Amberlyst-15 and H-Beta have been reported by Pinto et al. [46], but in this case, the authors focused the attention on the preparation of a mixture of MEG, DEG, and TEG to directly test the material obtained as a fuel additive. The results obtained in terms of the reduction of the cloud point and pour point when added to biodiesel show their potential for biodiesel formulations.

The use of arensulfonic acid-functionalized mesostructured silicas was explored by analyzing the influence of different reaction parameters, such as the temperature, ethanol/glycerol ratio, and catalyst loading, on the activity and selectivity [47]. The best results were obtained at $200{ }^{\circ} \mathrm{C}$ and for a high ethanol concentration and high catalyst loading.

Another typical reported Brønsted acid is tungstophspohric acid $\left(\mathrm{H}_{3} \mathrm{PW}_{12} \mathrm{O}_{40}, \mathrm{HPW}\right)$ and $\mathrm{HPW} / \mathrm{SiO}_{2}$ [48]. Although quite long reaction times are required, the authors obtained a very interesting conversion of up to $97.1 \%$, with a selectivity to the mono-, di-, and tri-ether, respectively, of $61.9 \%, 28.1 \$$, and $10 \%$ (Table 2, Entry 4). Interestingly, the catalyst is active also with water-containing glycerol, even though there is a lower conversion due to the hydrolysis reverse reaction being favored under the conditions used, which results in a mixture that contains up to $30 \%$ by wt of water with respect to ethanol. On the other hand, the presence of water allows a higher selectivity to be obtained for the monoether, raising it to $89.6 \%$ from $65.9 \%$.

Another interesting approach to the use of bioalcohols has been reported in the etherification of glycerol with butanol [49]. A commercial ion exchange resin was used in a reactor equipped with a membrane system for the water removal, which resulted in an improvement of the conversion despite a lower selectivity.

\section{The Use of Solid Acids in Furanic Ethers Synthesis}

Furanic ethers represent a very interesting class of compounds to be used as additives or diesel blends due to their biomass origin and to their good properties with respect to fuel requirements.

The need for biomass derived fuels has gained an ever-increasing importance in the last decades and, particularly in the diesel sector, the search for lignocellulosic derived materials that can act as an alternative to first generation vegetable oil based biodiesel is strongly encouraged. Actually, both the limited availability of renewable oils and their relative high cost makes the use of profusely available lignocellulosic feedstock an appealing method to be pursued [50]. The best candidates as fuel chemicals that are intermediate among the lignocellulose deconstruction stream are furfural (FA), 5-hydroxymethylfurfural (HMF), and levulinic acid (LA), and some main strategies aiming to improve 
the carbon skeleton structure to prepare products in the diesel-range from these platform molecules have been explored.

Due to the presence of the aldehydic group in FA and HMF, aldol condensation reactions are often used to increase the number of the $\mathrm{C}$ atom.

One possibility is the aldol condensation with ketones over basic catalysts [51,52], which allows the obtainment of C9-C15 molecules that can eventually be further hydrogenated to form alkane chains. The oligomerization of furans via acid catalyzed condensation has also been reported as a carbon-upgrading process [53]. The method of the formation of alkenes through $\gamma$-valerolactone obtained from levulinic acid is another viable route [54].

However, a different strategy can be envisaged based on the etherification of the alcoholic functionality in HMF or the one that can be obtained through the reduction of the aldehyde group in both FA and HMF (Scheme 4).

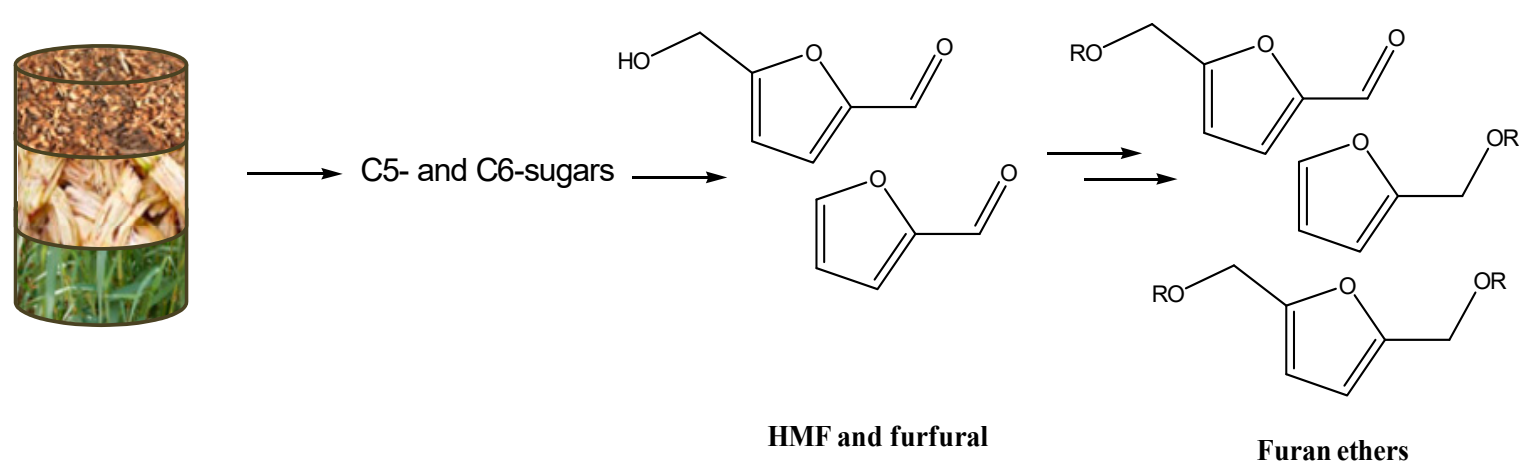

Scheme 4. The way to furan ethers from lignocellulosic biomass.

Indeed, the potential of 5-(ethoxymethyl)furfural studied by Avantium has been considered as a biofuel due to its high boiling point and its energy density (31.3 MJ/l). This value is higher than the one reported for ethanol (22 MJ/1) and comparable to standard gasoline $(34.2 \mathrm{MJ} / 1)$ and diesel fuel $(35.8 \mathrm{MJ} / \mathrm{l})$, and together with its boiling point of $235^{\circ} \mathrm{C}$, it makes this ether very attractive as a diesel fuel additive [55].

Inventors found a convenient way to furanic ethers starting directly from sugars by using acid catalysts at a high temperature in alcoholic solvents, thus preventing the formation of decomposition products from HMF, which are usually formed in water. Moreover, the high potential of furanic ethers as fuels and fuel additives has been surveyed by some of the same authors [56].

In particular, within the series of 5-(alkoxymethyl)furfural that are obtained with alcohols varying from $\mathrm{C} 1$ to $\mathrm{C} 8$, the blend's properties are improved by increasing the number of carbon atoms in the alcohol chain.

Diethers obtained by a second etherification of the reduced carbonyl group in HMF are even superior in terms of the blend's properties. When a bioalcohol is used for the ether formation, furanic ethers are $100 \%$ bio-based and do not lead to low-value by-products during the process preparation.

Moreover, according to the analysis reported by Lange et al. [57], among the mainly studied products of furan upgrading, ethyl furfuryl ether shows, for example, a very limited footprint in terms of $\mathrm{CO}_{2}$ emission and investment costs considering its preparation process, whereas the footprint increases significantly as the furan ring is saturated or opened to pentanols due to the significant capital intensity linked to the exothermicity of hydrogenation reactions. Therefore, ethers represent an interesting upgrade of furans to produce good gasoline components with a small footprint, whereas hydrogenated molecules entail a much larger footprint.

The preparation of furan ethers is also the idea behind a smart way identified by Mascal et al. to maximize the yield in HMF starting not only from glucose, but also from cellulose by limiting decomposition product formation [58]. The strategy is based on the conversion into 5-(chloromethyl)furfural (CMF) that, due to its hydrophobicity, is easily trapped by the organic solvent 
when working under biphasic conditions. Although $5 \mathrm{wt} \%$ of $\mathrm{LiCl}$ and concentrated $\mathrm{HCl}$ are used as catalysts, this strategy allows the obtainment of up to $80 \%$ in an intermediate that in turn can be directly used for the etherification reaction according to Scheme 5.
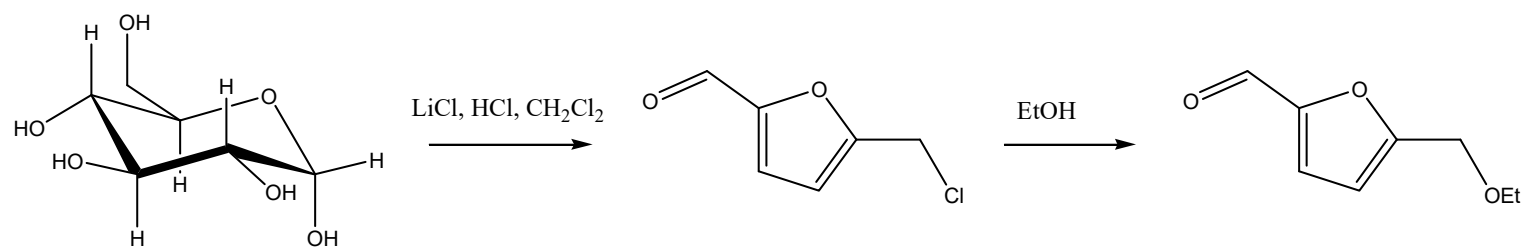

Scheme 5. Transformation of glucose into 5-(chloromethyl)-furfural and the following etherification with ethanol.

The use of $\mathrm{LiCl}$ and $\mathrm{HCl}$ is generally not desirable from the process management point of view, but the work certainly represents a pioneering step towards an efficient utilization of biomass to obtain useful fuel components. Thus, the reaction protocol can also be applied to C5 sugars and directly to raw biomass, such as straw, wood, or corn stover, as it is able to convert the cellulosic fraction irrespective of the other components present in the raw starting material [59].

Nevertheless, the method of forming ether via alcohol dehydration is the most explored one due to its intrinsic higher sustainability. As already mentioned the formation of unsymmetrical ethers by means of solid acid catalysts is a convenient route that has been explored in the last years.

\subsection{Direct Etherification of HMF and Furfural}

The first report relying on the use of solid acids for the etherification of HMF into the corresponding ethyl ether (Scheme 6) describes the use of different mesoporous acids, namely SBA-15, zirconium modified SBA-15, Al-MCM-41, and Amberlyst ${ }^{\circledR} 15$, at $140{ }^{\circ} \mathrm{C}$ [60] The authors observed significant changes in the desired ether yield depending on the acidic character of the catalyst used. In particular, over the catalysts expressing mainly Brønsted acidity, as is the case of Amberlyst ${ }^{\circledR} 15$ or Al-modified MCM41, ethyl levulinate was the main product obtained. On the other hand, the formation of the ethyl ether of HMF was associated with the presence of Lewis acid sites. Thus, with $\mathrm{Zr}$ modified SBA-15, the EMF yield reached $76 \%$. The influence of the reaction temperature on the selectivity in the presence of Pt catalysts, Amberlyst, and other sulfonic resins was studied by the group of Bell [61], who also extensively investigated the reaction mechanism.
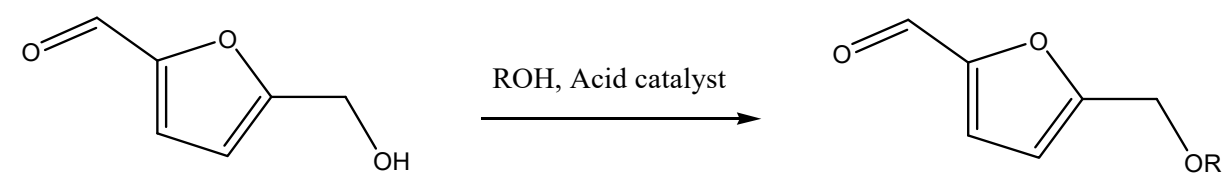

Scheme 6. Mono etherification of HMF.

Another explored strategy relies on the use of orthoesters as reagents. Traditionally, the reaction of an alcohol with an orthoester is exploited for the formation of C-C bonds via the Johnson-Claisen rearrangement, carried out at high temperatures in the presence of a weak acid under conditions for distillative removal of the alcohol formed [62]. On the other hand, the use of solid acids at low temperatures is also reported to promote the formation of ethers, both symmetrical and unsymmetrical ones, according to the general Scheme 7 [63].

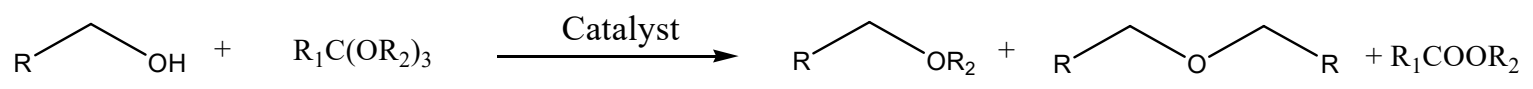

Scheme 7. General reaction of orthoesters with alcohols.

The authors tested the use of montmorillonite $\mathrm{KSF}$ and $\mathrm{K} 10, \mathrm{SiO}_{2}$ and amberlyst- 15 by observing important differences in the product ratio depending on the catalyst. In particular, a significant 
amount of the unsymmetrical ether of up to $90 \%$ was obtained in the presence of Montmorillonite KSF, thus suggesting the possibility of taking advantage of this protocol for ether synthesis when using a catalyst able to properly stabilize the cationic intermediate. Moreover, the great importance of carrying out the reaction at room temperature, instead of heating at high temperature, was identified in the same paper, as the same catalysts under reflux conditions led to messy reaction mixtures with a very poor ether selectivity.

The unraveled potential of the interaction of orthoester with alcohols in the presence of various solid acids, has been very recently exploited for the preparation of furanic ethers [64].

This approach was revealed to be effective for the preparation of both methyl and ethyl furfuryl ethers, allowing the reaction to be carried out at a low temperature with respect to the other protocols reported (Table 3, entries 4-7). Despite the disadvantages related to the use of a sacrificial reagent in terms of atom economy, the authors underline the unique potential of the protocol with respect to energy saving and selectivity.

Table 3. Comparison of catalytic procedures for furanic ethers by direct etherification.

\begin{tabular}{cccccccc}
\hline Entry & substrate & Catalyst & Reagent & T $\left({ }^{\circ} \mathbf{C}\right)$ & Conv & Yield \% & Ref \\
\hline 1 & HMF & Zr-SBA-15 & ethanol & 140 & 100 & 76 & {$[60]$} \\
2 & HMF & Amberlyst & ethanol & 110 & 100 & 71 & {$[61]$} \\
3 & Furfuryl alcohol & ZSM-5 & ethanol & 125 & 80 & 40 & {$[57]$} \\
4 & Furfuryl alcohol & ZSM-5 & CH(OMe $)_{3}$ & 40 & 92 & 73 & {$[64]$} \\
5 & Furfuryl alcohol & ZSM-5 & CH(OEt $)_{3}$ & 40 & 57 & 42 & {$[64]$} \\
6 & Furfuryl alcohol & ZSM-5 & CH $(\mathrm{OPr})_{3}{ }^{a}$ & 40 & 54 & 43 & {$[64]$} \\
7 & Furfuryl alcohol & ZSM-5 & $\mathrm{CH}(\mathrm{OBu})_{3}{ }^{a}$ & 40 & 49 & 37 & {$[64]$} \\
\hline \multicolumn{7}{c}{ Prepared in situ. }
\end{tabular}

Interestingly, the substrate scope can be extended by exploiting the capability of ZSM-5 to also promote orthoester exchange in the presence of alcohols. In this way, it is possible to design an orthoester exchange-etherification sequence in which the desired orthoester is produced in situ from trimethyl orthoformate and the corresponding alcohol without the need for prior synthesis and isolation.

\subsection{Cascade Processes from HMF and Furfural}

The great potential of cascade and one-pot processes using a bifunctional catalyst is an even more interesting path to be followed. One possibility is to directly start from furfural instead of the corresponding alcohol derived from the aldehyde by hydrogenation, or directly from sugars, namely glucose or fructose.

The direct etherification of a carbonyl group with an alcohol is a convenient route in a general way, especially in the case of aromatic compounds, as ketones are the first intermediates in the functionalization of aromatic hydrocarbons by means of the Friedel-Crafts acylation, as well as in the case of $\mathrm{C} 5$ platform molecules derived from biomass, such as HMF and furfural.

One of the first attempts in this direction was reported by the group of Bell [61]. The paper relies on the use of a one-pot reductive etherification protocol from HMF to 2,5-bis(alkoxymethyl)furan by using a mixture of two catalysts, namely a PtSn alloy supported on alumina and Amberlyst-15, under hydrogenation conditions, allowing the obtainment of $64 \%$ of the ether by using ethanol and $47 \%$ by using butanol (Table 4, entries 1 and 2).

The analysis of the reaction mixture also shows that in the presence of a metal based reducing catalyst, the reaction follows a reductive etherification pathway rather than a sequential carbonyl reduction to the BHMF, according to Scheme 8. 


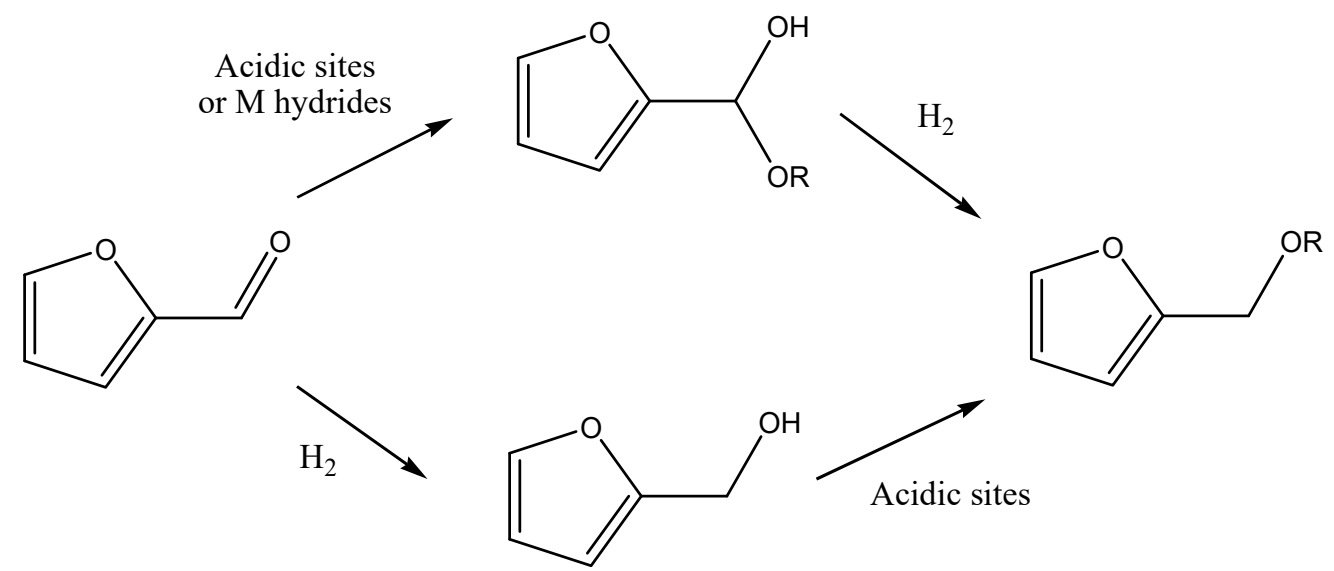

Scheme 8. Possible reaction pathway for the reductive etherification of furfural.

The use of a unique system that is able to promote the whole transformation is, of course, a desirable target and this possibility was investigated by Li et al. [65] by exploiting the hydrogenation activity and Lewis acidity retained by a reduced commercial $\mathrm{Co}_{3} \mathrm{O}_{4}$ due to the coexistence of $\mathrm{Co}^{0}$ and $\mathrm{Co}^{2+/ 3+}$ species. The authors ascribe the strength of the protocol proposed to the moderate Lewis acidic character of the reduced Co. Under optimized conditions, that is $140{ }^{\circ} \mathrm{C}$ and $2 \mathrm{MPa}$ of $\mathrm{H}_{2}$, $98.5 \%$ of the diether was obtained at full conversion of HMF. XPS analysis confirmed the presence of both $\mathrm{Co}^{0}$ and $\mathrm{Co}^{2+/ 3+}$ species after the reduction of $\mathrm{Co}_{3} \mathrm{O}_{4}$, which endows the catalyst not only with a hydrogenation activity, but also with an etherification capacity.

Some other work within reductive etherification under hydrogenation conditions with metal catalysts has been carried out using furfural as the substrate, which found good candidates for this application in Pd based systems [66].

In particular, a commercial $\mathrm{Pd}$ on charcoal was the most performing among a series of $\mathrm{Cu}$, Ir, $\mathrm{Ni}, \mathrm{Pt}$, and Pd samples when tested with methanol for the direct transformation of furfural into 2-methoxymethylfuran and was obtained with a 77\% selectivity. The effectiveness of charcoal mainly derives from the acidic functionalities present in the form of surface oxides, which play a crucial role in the mechanism of ether formation via hemiacetal, as already shown for other substrates [67] and already invoked for HMF when Brønsted acidic systems are used as catalysts [61].

On the other hand, other authors, while also endorsing the hypothesis of the hemiacetal pathway, mainly ascribe the acetalisation reaction to Pd hydrides formed under $\mathrm{H}_{2}$ atmosphere, when working at low temperatures [68]. A $0.7 \mathrm{wt} \% \mathrm{Pd} / \mathrm{C}$ at $60{ }^{\circ} \mathrm{C}$ and $0.3 \mathrm{MPa}$ of $\mathrm{H}_{2}$ gave $81 \%$ of furfuryl ethyl ether by this particular capacity. Also, a catalyst of palladium supported on hydroxyapatite was reported to promote the formation of furfuryl isopropyl ether as an intermediate in the way of complete hydrogenation of furfural to tetrahydrofurfuryl alcohol when working under low hydrogen pressure [69].

However, while the hydrogenation of furfural and HMF in this kind of cascade reaction requires a super-atmospheric pressure of $\mathrm{H}_{2}$, hydrogen transfer conditions are very suitable for the reduction of the aldehyde group. The use of an alcohol as a hydrogen donor and as a solvent can effectively boost the formation of ether when the catalyst shows finely tuned acid-base properties.

In fact, a catalyst able to promote the Meerwein-Ponndorf-Verley reduction of furfural while also favoring the following dehydration of the alcohols allows one the establishment of a one pot process for the synthesis of asymmetrical furanic ethers. This strategy overcomes the use of both a noble metal based catalyst and high hydrogen pressures for the hydrogenation step.

Typically, heterogeneous catalysts that are able to establish a hydrogen transfer reaction and that possess Lewis acid features are framework substituted Sn or Zr zeolites [70-72].

Sn-Beta was reported for the one pot transformation of HMF into different bis-alkoxy ethers, with a yield of up to $80 \%$ in the desired product [73]. Some interesting points were raised from the 
study of the reaction conditions. The reaction temperature was identified as a useful parameter to increase the $\mathrm{HMF}$ conversion, reaching $98.3 \%$ at $210{ }^{\circ} \mathrm{C}$, however, the maximization of selectivity toward the bis-ether $(87 \%)$ reached $180^{\circ} \mathrm{C}$. It is also interesting to note that the reaction protocol can be applied to both primary and secondary alcohols, with a slightly lower selectivity with the latter ones due to the minor hydrogen transfer activity.

The outstanding performances of Sn-Beta in this process are ascribed to its Lewis acidic character. Thus, the comparison with an Al-Beta system shows that when Brønsted acidic sites are also present, selectivity drops in favor of the monoether as the major product, thus revealing the low activity of the Meerwein-Ponndorf activity of Brønsted sites. The effect of acidity on the selectivity was elucidated in an even deeper study by some of the same authors by comparing $\mathrm{Al}_{2} \mathrm{O}_{3}, \mathrm{Al}_{2} \mathrm{O}_{3} / \mathrm{SBA}-15, \mathrm{ZrO}_{2}$, $\mathrm{ZrO}_{2} / \mathrm{SBA}-15, \mathrm{TiO}_{2}, \mathrm{TiO}_{2} / \mathrm{SBA}-15, \mathrm{H}-\mathrm{BEA}$, and Sn-BEA in the reaction of HMF with 2-propanol under flow conditions [74].

The authors restate that strong Brønsted sites, as those observed on $\mathrm{H}-\mathrm{BEA}$ or $\mathrm{Al}_{2} \mathrm{O}_{3} / \mathrm{SBA}-15$, catalyze the formation of mono-ether, without carbonyl hydrogenation, and weak Brønsted systems present on $\mathrm{ZrO}_{2}$ and $\mathrm{TiO}_{2}$ supported on SBA-15 promote the formation of the ether following the HT reaction, while solids containing only Lewis sites, such as Sn-BEA, were revealed as the most active in both HT and the dehydration reaction, giving a high yield of the bis ether (Scheme 9).

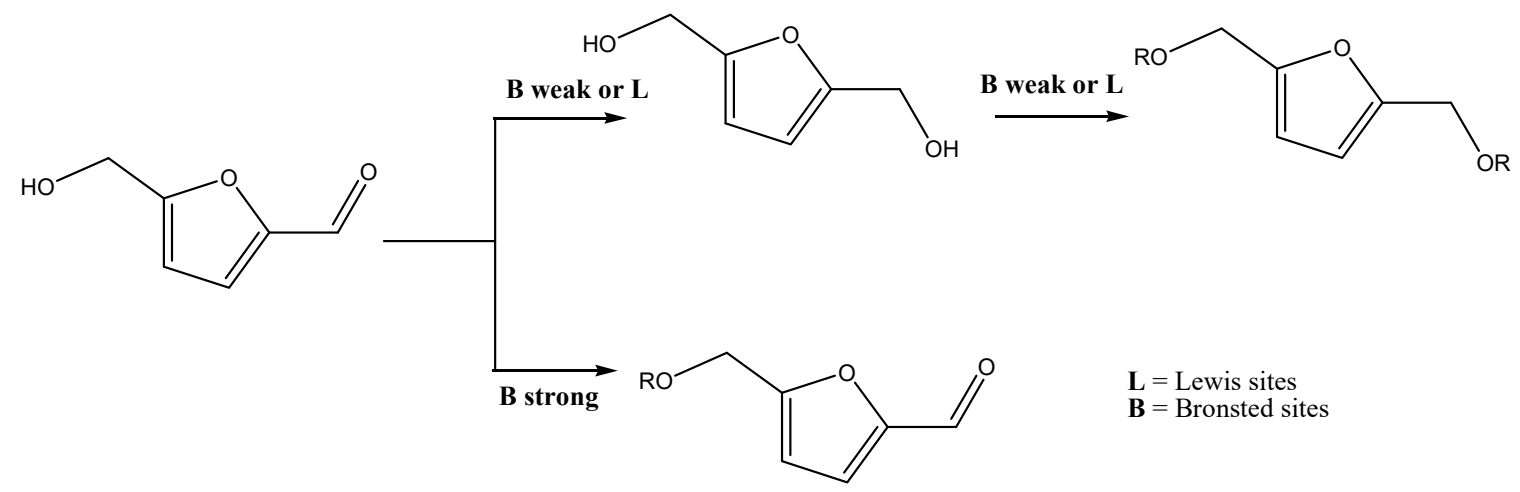

Scheme 9. Main products obtained by varying the acidity of the catalytic system.

When using a Zr-SBA-15 catalyst possessing Lewis acid features due to the presence of $\mathrm{Zr}^{4+}$ sites, interesting results in both HT and etherification were also obtained by using furfural as the substrate [75]. A yield of $85 \%$ in $i$-propyl-furfuryl-ether was obtained at $130^{\circ} \mathrm{C}$ with a $1: 1$ furfural to catalyst mass ratio.

A smart demonstration of the role of Lewis and Brønsted sites in the two reactions was obtained with metal chlorides, such as $\mathrm{CrCl}_{3}$ and $\mathrm{YbCl}_{3}$, by a kinetic study in conjunction with salt speciation using a soft ionization mass spectrometer [76]. Thus, the Brønsted acidic species generated from the alcoholysis of the metal chlorides were shown to be predominant catalytically active species in the etherification.

On the other hand, the right tradeoff between Lewis and Brønsted acidity was also exploited by using a mixture of two catalysts, namely $\mathrm{ZrO}(\mathrm{OH})_{2}$ and $\mathrm{Zr}$-montmorillonite, respectively, ruling out the hydrogen transfer reaction and the etherification one [77]. This combination allowed the authors to obtain an excellent yield in the bis-ether, particularly by using secondary alcohols, such as 2-propanol and 2-butanol. The significant difference in activity observed with the secondary and primary alcohols was mainly ascribed to the better performances of the former in the hydrogen transfer activity.

The possibility to switch the selectivity towards different products based on the different acidic properties of the catalytic material used was also underlined by some authors by using $\mathrm{ZrO}_{2}$ and $\mathrm{SiO}_{2}-\mathrm{ZrO}_{2}$ in the reaction of furfural with 2-butanol under hydrogen transfer conditions (Table 4, entries 15 and 16) [78]. Moving from $\mathrm{ZrO}_{2}$ to $\mathrm{SiO}_{2}-\mathrm{ZrO}_{2}$ under the same reaction conditions allowed the authors to respectively obtain $100 \%$ furfuryl alcohol or $87 \%$ of the ether by the genuine Lewis acid 
character shown by zirconia dispersed on silica, in agreement with the conclusions drawn by the use of Sn-Beta [74].

The effectiveness of Lewis acidity in promoting both reactions was confirmed using a copper supported catalyst, $\mathrm{Cu} / \mathrm{SiO}_{2}$ [78]. This catalyst possesses a peculiar Lewis acidic character based on the very high dispersion of the metallic phase, already exploited in the one-pot transformation of $\gamma$-valerolactone into valeric esters [79] and the cascade direct etherification of aromatic ketones with different alcohols [80].

Table 4. Comparison of catalytic procedures for furanic ethers by the cascade process starting from furfural or HMF.

\begin{tabular}{|c|c|c|c|c|c|c|c|c|c|}
\hline & Catalyst & Reagent & $\begin{array}{l}\text { Reduction } \\
\text { Condtions }\end{array}$ & Alcohol & Product & $\begin{array}{c}\mathrm{T} \\
\left({ }^{\circ} \mathrm{C}\right)\end{array}$ & Conv $\%$ & Yield \% & Ref \\
\hline 1 & $\begin{array}{c}\mathrm{PtSn} / \mathrm{Al}_{2} \mathrm{O}_{3}+ \\
\text { Amberlyst15 }\end{array}$ & HMF & $\mathrm{H}_{2} 1.4 \mathrm{MPa}$ & ethanol & & 60 & - & 64 & [61] \\
\hline 2 & - & HMF & $\mathrm{H}_{2} 1.4 \mathrm{MPa}$ & n-butanol & & 60 & - & 47 & [61] \\
\hline 3 & Reduced Co & $\mathrm{HMF}$ & $\mathrm{H}_{2} 2 \mathrm{MPa}$ & Methanol & & 140 & 100 & 98.5 & [65] \\
\hline 4 & $\mathrm{Pd} /$ charcoal & furfural & $\mathrm{H}_{2} 5 \mathrm{MPa}$ & methanol & & $\begin{array}{c}80 \\
-120\end{array}$ & - & $77^{\mathrm{a}}$ & [66] \\
\hline 5 & $\mathrm{Pd} / \mathrm{C}$ & furfural & $\mathrm{H}_{2} 0.3 \mathrm{MPa}$ & ethanol & & 60 & 98 & 81 & [68] \\
\hline 6 & Pd-HAP & furfural & $\mathrm{H}_{2} 1 \mathrm{MPa}$ & 2-propanol & & 40 & 98 & 60 & [69] \\
\hline 7 & Sn-Beta & HMF & HT & 2-propanol & & 180 & 70 & 87 & [74] \\
\hline 8 & $\begin{array}{l}\mathrm{Zr}-\mathrm{Mont}+ \\
\mathrm{ZrO}(\mathrm{OH})_{2}\end{array}$ & HMF & HT & 2-propanol & & 160 & 100 & 95 & [77] \\
\hline 9 & $\begin{array}{l}\mathrm{Zr}-\mathrm{Mont}+ \\
\mathrm{ZrO}(\mathrm{OH})_{2}\end{array}$ & HMF & HT & 2-butanol & & 150 & 100 & 96 & [77] \\
\hline 10 & $\begin{array}{l}\mathrm{Zr}-\mathrm{Mont}+ \\
\mathrm{ZrO}(\mathrm{OH})_{2}\end{array}$ & HMF & HT & n-butanol & & 150 & 100 & 49 & [77] \\
\hline 11 & $\begin{array}{l}\mathrm{Zr}-\mathrm{Mont}+ \\
\mathrm{ZrO}(\mathrm{OH})_{2}\end{array}$ & HMF & HT & ethanol & & 150 & 100 & 0 & [77] \\
\hline 12 & $\begin{array}{l}\mathrm{Zr}-\mathrm{Mont}+ \\
\mathrm{ZrO}(\mathrm{OH})_{2}\end{array}$ & furfural & HT & 2-propanol & & 100 & 100 & 67 & [77] \\
\hline 13 & $\begin{array}{l}\mathrm{Zr}-\mathrm{Mont}+ \\
\mathrm{ZrO}(\mathrm{OH})_{2}\end{array}$ & furfural & HT & 2-butanol & & 100 & 100 & 69 & [77] \\
\hline 14 & Zr-SBA-15 & furfural & HT & 2-propanol & & 130 & 95 & 84 & [75] \\
\hline 15 & $\mathrm{SiO}_{2}-\mathrm{ZrO}_{2}$ & furfural & HT & 2-butanol & & 140 & 80 & 81 & [78] \\
\hline 16 & $\mathrm{Cu} / \mathrm{SiO}_{2}$ & furfural & HT & 2-butanol & & 180 & 72 & 50 & [78] \\
\hline
\end{tabular}

a Selectivity; HT = Hydrogen Transfer.

Certainly, the use of metallic supported catalysts, such as Pd/C (Table 4, entry 5), under hydrogenation conditions allows the obtainment of excellent results in terms of both conversion and selectivity at low reaction temperatures. On the other hand, the use of noble metals and $\mathrm{H}_{2}$ for this kind of application was revealed as expensive and less fitting with respect to zirconium containing materials. Systems, such as $\mathrm{Zr}-\mathrm{SBA}-15$ and $\mathrm{SiO}_{2}-\mathrm{ZrO}_{2}$ (Table 4, entries 14 and 15), suffer from a lower 
activity, thus requiring higher temperatures, however, they allow work to occur under hydrogen transfer conditions and obtain a very good yield of the product by their bifunctional acidic behaviour.

The fine tuning of the acidic properties of the catalysts as far as both strength and density is concerned, as well as their Lewis or Brønsted character, becomes a central issue in their application to biomass derived materials. The target of an efficient acid catalyst for etherification reactions that are able to substitute the traditional processes poses a challenge when faced with substrates, such as furfural or HMF. Actually, their poor stability in the presence of acids represents a strong limitation when working under harsh conditions due to their tendency to form humins [81]. On the other hand, the moderate temperatures used for the synthesis of ethers do not favor this kind of product and the presence of the alcohol, used also as the solvent, strongly prevents some undesired reaction pathways, such as the polymerization one. [82]. Nevertheless, two main by-products compete with the desired ethers, namely the acetal and alkyl levulinate, as shown in Scheme 10. Comparable and even more complex considerations can be drawn in the case of HMF [76].

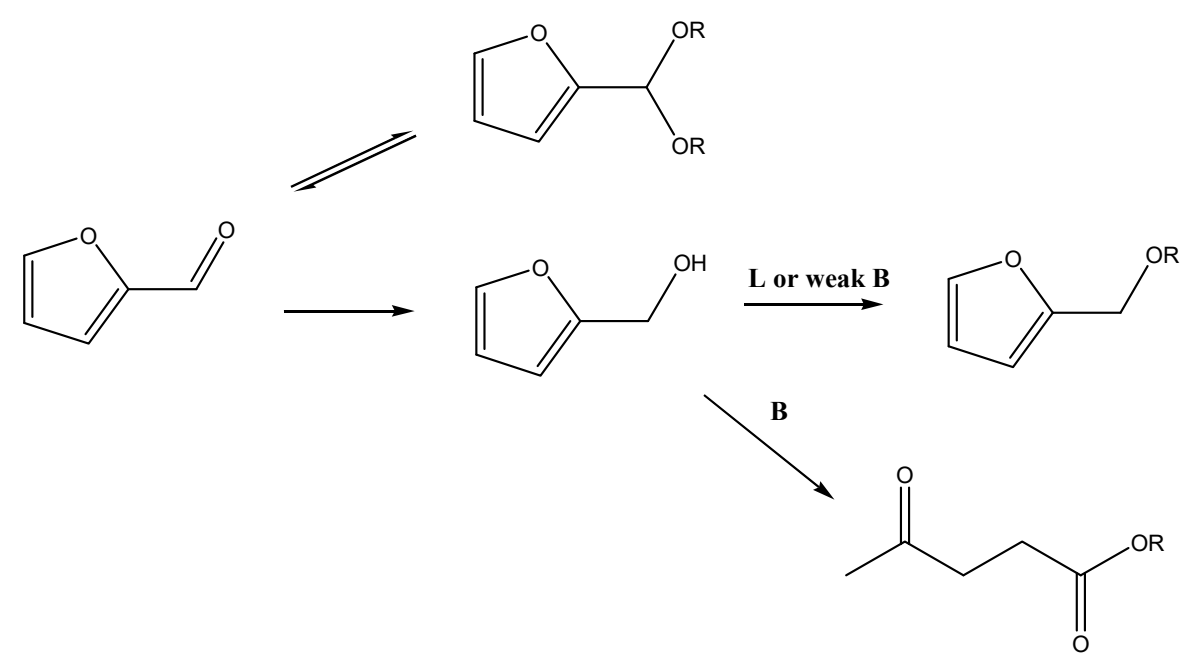

Scheme 10. Possible products obtained in the reductive etherification of furfural.

Alkyl levulinate formation is mainly promoted by Brønsted acid sites, while the etherification mainly relies on Lewis sites. A detailed study in this mechanistic study was reported by the group of Centi, showing the existence of a quantitative relationship between the numbers of Lewis and Brønsted sites and their catalytic performance in the etherification of HMF with ethanol considering the possible products [83].

Starting from these points the choice of the proper acidity of solid materials, as well as the characterisation of acidic features, rule on the selectivity of the process. This would result to be also the most challenging aspect when planning a process starting directly from sugars or from biomass that often request Brønsted acidity for the first deconstruction steps.

\subsection{Cascade Processes from C6 and C5 Sugars}

The pivotal role of acidity and the proper combination of different acidic characters is even more important in the design of the three step cascade process for the preparation of ethers starting from $\mathrm{C} 5$ and $\mathrm{C} 6$ sugars, which is the most rewarding way in terms of both process intensification and selectivity improvement considering the advantage obtained in avoiding the isolation of HMF and furfural.

Some attempts in this direction were already reported in the early paper from Balakrishnan et al. [59] by using the two-catalyst system of $\mathrm{PtSn} / \mathrm{Al}_{2} \mathrm{O}_{3}+$ Amberlyst- 15 under hydrogenation conditions. In this protocol, an ethanolic or butanolic suspension of D-(-)-fructose, Amberlyst-15, and $\mathrm{PtSn} / \mathrm{Al}_{2} \mathrm{O}_{3}$ were heated at $110{ }^{\circ} \mathrm{C}$ for 30 hours. After, the formation of ether and acetals as intermediates was observed the mixture and was cooled down to $60{ }^{\circ} \mathrm{C}$ and put under $1.4 \mathrm{MPa}$ of $\mathrm{H}_{2}$, thus obtaining the diether in a $47-51 \%$ yield and, therefore, exploiting a one-pot, two-step process. 
The use of a single catalyst was on the other hand reported in a recent paper by Bai et al., relying on the use of a hierarchical zeolite with a controlled meso-/microporous morphology MFI-Sn/Al (Scheme 11) [84].<smiles>C#CCO[C@H]1O[C@H](CO)[C@@H](C)[C@H](O)[C@H]1O</smiles>

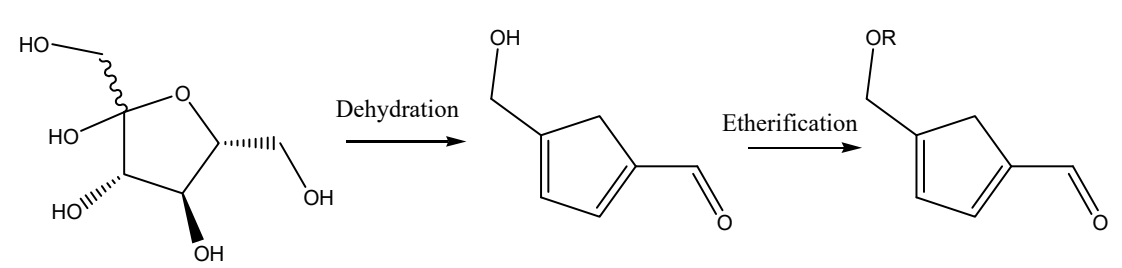

Scheme 11. One-pot transformation of glucose into HMF ether.

The catalyst proposed contains dual meso-/microporosity and dual Lewis and Brønsted acidity able to promote isomerisation of glucose to fructose, the following dehydration to HMF, and the final etherification to monoether with methanol in a $44 \%$ yield.

The coexistence of a dual acidic capacity confirms the importance of this aspect when several acid catalyzed steps are involved, as is the case of sugars to ethers. The cascade process entails isomerisation, dehydration, etherification, and reduction, transformations that are dependent on different kinds of acid sites. The role of Brønsted acids in the domino transformation of fructose into ethoxy-methyl-furfural was also studied by computational methods, identifying that the protonated solvent $\left[\mathrm{C}_{2} \mathrm{H}_{5} \mathrm{OH}_{2}\right]^{+}$is in fact the catalytically active species [85].

\section{Conclusions}

Biofuels will have a very important role in decarbonising the transport sector in the next 30 years as electrification will play a major role, but it is not applicable to all sectors. On the other hand, the production of bio-alcohols through fermentation processes, particularly ethanol from cellulosic biomass and ethanol/butanol mixture through ABE fermentation of starch and glucose, is growing continuously. Butanol and longer chain alcohols can also be obtained through Guerbet reactions of bio-ethanol [86], 2-pentanol [87], and furfurilic alcohol from furfural, in turn obtained from hemicellulose together with HMF. Some of these bioalcohols can be used as biofuels themselves, but upgrading them through the synthesis of ethers would greatly improve their performance.

The use of solid acids, which are very widespread in oil refining, will also play a relevant role in the production of fuels and fuel additives from renewables. Solids with a good hydrothermal stability and a proper distribution of acidic sites can give excellent results as catalysts for ether synthesis in a biorefinery scenario.

Author Contributions: Conceptualization, F.Z. and N.R.; Writing-Original Draft Preparation, F.Z. and N.S.; Writing-Review \& Editing, N.R.

Funding: This research received no external funding.

Conflicts of Interest: The authors declare no conflict of interest.

\section{References}

1. Awad, O.I.; Mamat, R.; Ibrahim, T.K.; Hammid, A.T.; Yusri, I.M.; Hamidi, M.A.; Humada, A.M.; Yusop, A.F. Overview of the oxygenated fuels in spark ignition engine: Environmental and performance. Renew. Sustain. Energy Rev. 2018, 91, 394-408. [CrossRef]

2. Awad, O.I.; Mamat, R.; Ali, O.M.; Sidik, N.A.C.; Yusaf, T.; Kadirgama, K.; Kettner, M. Alcohol and ether as alternative fuels in spark ignition engine: A review. Renew. Sustain. Energy Rev. 2018, 82, 2586-2605. [CrossRef]

3. Mahdi, H.I.; Muraza, O. Conversion of isobutylene to octane-booster compounds after methyl tert-butyl ether phaseout: The role of heterogeneous catalysis. Ind. Eng. Chem. Res. 2016, 55, 11193-11210. [CrossRef] 
4. Pal, D.B.; Lavania, R.; Srivastava, P.; Singh, P.; Srivastava, K.R.; Madhav, S.; Mishra, P.K. Photo-catalytic degradation of methyl tertiary butyl ether from wastewater using $\mathrm{CuO} / \mathrm{CeO}_{2}$ composite nanofiber catalyst. J. Environ. Chem. Eng. 2018, 6, 2577-2587. [CrossRef]

5. Saravanan, K.; Ham, H.; Tsubaki, N.; Bae, J.W. Recent progress for direct synthesis of dimethyl ether from syngas on the heterogeneous bifunctional hybrid catalysts. Appl. Catal. B: Environ. 2017, 217, 494-522. [CrossRef]

6. Renewable Fuels Associations, Ethanol Market. Available online: https://ethanolrfa.org/resources/ industry/statistics/\#1537811482060-17cad4ed-d2ca (accessed on 11 February 2019).

7. Gavahian, M.; Munekata, P.E.S.; Eş, I.; Lorenzo, J.M.; Khaneghah, A.M.; Barba, F.J. Emerging techniques in bioethanol production: From distillation to waste valorization. Green Chem. 2019. [CrossRef]

8. Bankar, S.B.; Survase, S.A.; Ojamo, H.; Granström, T. Biobutanol: The outlook of an academic and industrialist. RSC Adv. 2013, 3, 24734. [CrossRef]

9. Chozhavendhan, S.; Kumar, R.P.; Elavazhagan, S.; Barathiraja, B.; Jayakumar, M.; Varjani, S.J. Utilization of Crude Glycerol from Biodiesel Industry for the Production of Value-Added Bioproducts. In Waste to Wealth; Springer: Singapore, 2017; pp. 65-82.

10. Melero, J.A.; Vicente, G.; Morales, G.; Paniagua, M.; Javier Bustamante, J. Oxygenated compounds derived from glycerol for biodiesel formulation: Influence on EN 14214 quality parameters. Fuel 2010, 89, 2011-2018. [CrossRef]

11. Leitner, W.; Klankermayer, J.; Pischinger, S.; Pitsch, H.; Kohse-Höinghaus, K. Advanced biofuels and beyond: Chemistry solutions for propulsion and production. Angew. Chem. Int. Ed. 2017, 56, 5412-5452. [CrossRef]

12. Bhanja, P.; Bhaumik, A. Porous nanomaterials as green catalyst for the conversion of biomass to bioenergy. Fuel 2016, 185, 432-441. [CrossRef]

13. Safari, M.; Nikazar, M.; Dadvar, M. Photocatalytic degradation of methyl tert-butyl ether (MTBE) by Fe-TiO 2 nanoparticles. J. Ind. Eng. Chem. 2013, 19, 1697-1702. [CrossRef]

14. Horvath, T.; Seiler, M.; Hunger, M. A comparative study of methyl-tert-butyl ether synthesis on zeolites HY, HBeta, HBeta/F and HZSM-5 by in situ MAS NMR spectroscopy under flow conditions and on-line gas chromatography. Appl. Catal. A Gen. 2000, 193, 227-236. [CrossRef]

15. Goodwin, J.G., Jr.; Natesakhawat, S.; Nikolopoulos, A.A.; Kim, S.Y. Etherification on Zeolites: MTBE synthesis. Catal. Rev. 2002, 44, 287-320. [CrossRef]

16. Nikolopoulos, A.A.; Kegelbauer, A.; Goodwin, J.G., Jr.; Marcelin, G. Effect of dealumination on the catalytic activity of acid zeolites for the gas phase synthesis of MTBE. Appl. Catal. A: Gen. 1994, 119, 69-81. [CrossRef]

17. Xu, B.; Bordiga, S.; Prins, R.; van Bokhoven, J.A. Effect of framework Si/Al ratio and extra-framework aluminum on the catalytic activity of Y zeolite. Appl. Catal. A: Gen. 2007, 333, 245-253. [CrossRef]

18. Nikolopoulos, A.A.; Kegelbauer, A.; Goodwin, J.G., Jr.; Marcelin, G. Gas phase synthesis of MTBE on triflic acid modified zeolites. J. Catal. 1996, 158, 76-82. [CrossRef]

19. Nikolopoulos, A.A.; Kegelbauer, A.; Goodwin, J.G., Jr.; Marcelin, G. Gas phase synthesis of MTBE on fluoride-modified zeolites. Catal. Lett. 1996, 39, 173-178. [CrossRef]

20. Collignon, F.; Mariani, M.; Moreno, S.; Remy, M.; Poncelet, G. Gas Phase Synthesis of MTBE from Methanol and Isobutene over Dealuminated Zeolites. J. Catal. 1997, 166, 53-66. [CrossRef]

21. Zhang, Q.; Xia, Q.-H.; Lu, X.-H.; Ma, X.-T.; Su, K.-X. Gas-phase catalytic synthesis of MTBE from MeOH and $\mathrm{Bu}^{t} \mathrm{OH}$ over various microporous H-zeolites. Indian J. Chem. 2009, 48, 788-792.

22. Xia, Q.-H.; Hidajat, K.; Kawi, S. Structure, Acidity, and Catalytic Activity of Mesoporous Acid Catalysts for the Gas-Phase Synthesis of MTBE from MeOH and Bu ${ }^{t} \mathrm{OH}$. J. Catal. 2002, 209, 433-444. [CrossRef]

23. Yee, K.F.; Mohamed, A.R.; Tan, S.H. A review on the evolution of ethyl tert-butyl ether (ETBE) and its future prospects. Renew. Sustain. Energy Rev. 2013, 22, 604-620. [CrossRef]

24. Khadzhiev, S.N.; Ezhova, N.N.; Yashina, O.V. Catalysis in the Dispersed Phase: Slurry Technology in the Synthesis of Dimethyl Ether. Petroleum Chem. 2017, 57, 553-570. [CrossRef]

25. Olah, G.A.; Goeppert, A.; Surya Prakash, G.K. Chemical Recycling of Carbon Dioxide to Methanol and Dimethyl Ether: From Greenhouse Gas to Renewable, Environmentally Carbon Neutral Fuels and Synthetic Hydrocarbons. J. Org. Chem. 2009, 74, 487-498. [CrossRef] [PubMed]

26. Sun, J.; Yang, G.; Yoneyama, Y.; Tsubaki, N. Catalysis Chemistry of dimethyl ether synthesis. ACS Catal. 2014, 4, 3346-3356. [CrossRef] 
27. Kang, M.; Bhen, A. Kinetics and mechanisms of alcohol dehydration pathways on alumina materials. Catal. Sci. Technol. 2016, 6, 6667-6678. [CrossRef]

28. Larmier, K.; Nicolle, A.; Chizallet, C.; Cadran, N.; Maury, S.; Lamic-Humblot, A.-F.; Marceau, E.; Lauron-Pernot, H. Influence of Coadsorbed Water and Alcohol Molecules on Isopropyl Alcohol Dehydration on $\gamma$-Alumina: Multiscale Modeling of Experimental Kinetic Profiles. ACS Catal. 2016, 6, 1905-1920. [CrossRef]

29. Seo, C.W.; Jung, K.D.; Lee, K.Y.; Yoo, K.S. Influence of Structure Type of $\mathrm{Al}_{2} \mathrm{O}_{3}$ on Dehydration of Methanol for Dimethyl Ether Synthesis. Ind. Eng. Chem. Res. 2008, 47, 6573-6578. [CrossRef]

30. Khom-in, J.; Praserthdam, P.; Panpranot, J.; Mekasuwandumrong, O. Dehydration of methanol to dimethyl ether over nanocrystalline $\mathrm{Al}_{2} \mathrm{O}_{3}$ with mixed $\gamma$ - and $\chi$-crystalline phases. Catal. Commun. 2008, 9, 1955-1958. [CrossRef]

31. Ramos, F.S.; Duarte de Farias, A.M.; Borges, L.E.P.; Monteiro, J.L.; Fraga, M.A.; Sousa-Aguiar, E.F.; Appel, L.G. Role of dehydration catalyst acid properties on one-step DME synthesis over physical mixtures. Catal. Today 2005, 101, 39-44. [CrossRef]

32. Vishwanathan, V.; Jun, K.-W.; Kim, J.-W.; Roh, H.-S. Vapour phase dehydration of crude methanol to dimethyl ether over Na-modified H-ZSM-5 catalysts. Appl. Catal. A: Gen. 2004, 276, 251-255. [CrossRef]

33. Jin, D.; Zhu, B.; Hou, Z.; Fei, J.; Lou, H.; Zheng, X. Dimethyl ether synthesis via methanol and syngas over rare earthmetals modified zeolite $\mathrm{Y}$ and dual Cu-Mn-Zn catalysts. Fuel 2007, 86, 2707-2713. [CrossRef]

34. Sutter, M.; Da Silva, E.; Duguet, N.; Raoul, Y.; Métay, E.; Lemaire, M. Glycerol Ether Synthesis: A Bench Test for Green Chemistry Concepts and Technologies. Chem. Rev. 2015, 115, 8609-8651. [CrossRef] [PubMed]

35. Li, R.; Song, H.; Chen, J. Propylsulfonic Acid Functionalized SBA-15 Mesoporous silica as efficient catalysts for the acetalization of glycerol. Catalysts 2018, 8, 297. [CrossRef]

36. Garcì, E.; Laca, M.; Perez, E.; Garrido, A.; Peinado, J. New Class of Acetal Derived from Glycerin as a Biodiesel Fuel Component. Energy Fuels 2008, 22, 4274-4280. [CrossRef]

37. Klepáčová, K.; Mravec, D.; Bajus, M. tert-Butylation of glycerol catalysed by ion-exchange resins. Appl. Catal. A: Gen. 2003, 45, 54-57. [CrossRef]

38. Klepáčová, K.; Mravec, D.; Kaszonyi, A.; Bajus, M. Etherification of glycerol and ethylene glycol by isobutylene. Appl. Catal. A: Gen. 2007, 328,1-13. [CrossRef]

39. Karinen, R.S.; Krause, A.O.I. New biocomponents from glycerol. Appl. Catal. A: Gen. 2006, 306, $128-133$. [CrossRef]

40. Frusteri, F.; Arena, F.; Bonura, G.; Cannilla, C.; Spadaro, L.; Di Blasi, O. Catalytic etherification of glycerol by tert-butyl alcohol to produce oxygenated additives for diesel fuel. Appl. Catal. A: Gen. 2009, 367, 77-83. [CrossRef]

41. Estevez, R.; López, M.I.; Jiménez-Sanchidrián, C.; Luna, D.; Romero-Salguero, F.J. Etherification of glycerol with tert-butyl alcohol over sulfonated hybrid silicas. Appl. Catal. A: Gen. 2016, 526, 155-166. [CrossRef]

42. Manjunathan, P.; Kumar, M.; Churipard, S.R.; Sivasankaran, S.; Shanbhag, G.V.; Maradur, S.P. Catalytic etherification of glycerol to tert-butyl glycerol ethers using tert-butanol over sulfonic acid functionalized mesoporous polymer. RSC Adv. 2016, 6, 82654-82660. [CrossRef]

43. Magar, S.; Kamble, S.; Mahanraj, G.T.; Jana, S.K.; Rode, C. Solid-Acid-Catalysed etherification of glycerol to potential fuel additives. Energy Fuel 2017, 31, 12272-12277. [CrossRef]

44. Pariente, S.; Tanchoux, N.; Fajula, F. Etherification of glycerol with ethanol over solid acid catalysts. Green Chem. 2008, 11, 1256-1261. [CrossRef]

45. Mravec, S.; Turana, T.; Filková, A.; Mikesková, N.; Volkovicsová, E.; Onyestyák, G.; Harnos, S.; Lónyi, F.; Valyon, J.; Kaszonyi, A. Catalytic etherification of bioglycerol with bioethanol over H-Beta, H-Y and H-MOR zeolites. Fuel Process. Technol. 2017, 59, 111-117. [CrossRef]

46. Pinto, B.P.; de Lyra, J.T.; Nascimento, J.A.C.; Mota, C.J.A. Ethers of glycerol and ethanol as bioadditives for biodiesel. Fuel 2016, 168, 76-80. [CrossRef]

47. Melero, J.A.; Vicente, G.; Paniagua, M.; Morales, G.; Muñoz, P. Etherification of biodiesel-derived glycerol with ethanol for fuel formulation over sulfonic modified catalysts. Bioresour. Technol. 2012, 103, 142-151. [CrossRef] [PubMed]

48. Yuan, Z.; Xia, S.; Chen, P.; Hou, Z.; Zheng, X. Etherification of Biodiesel- based glycerol with bioethanol over tungstophosphoric acid to synthesize glyceryl ethers. Energy Fuels 2011, 25, 3186-3191. [CrossRef] 
49. Cannilla, C.; Bonura, G.; Frusteri, L.; Frusteri, F. Batch reactor coupled with water permselective membrane: Study of glycerol etherification reaction with butanol. Chem. Eng. J. 2015, 282, 187-193. [CrossRef]

50. Alonso, D.M.; Bond, J.Q.; Dumesic, J.A. Catalytic Conversion of Biomass to Biofuels. Green Chem. 2010, 12, 1493-1513. [CrossRef]

51. Kikhtyanin, O.; Kadlec, D.; Velvarská, R.; Kubička, D. Using Mg-Al Mixed Oxide and Reconstructed Hydrotalcite as Basic Catalysts for Aldol Condensation of Furfural and Cyclohexanone. Chem CatChem 2018, 10, 1464-1475. [CrossRef]

52. Kikhtyanin, O.; Bulánek, R.; Frolich, K.; Čejka, J.; Kubička, D. Aldol condensation of furfural with acetone over ion-exchanged and impregnated potassium BEA zeolites. J. Mol. Catal. A: Gen. 2016, 424, 358-368. [CrossRef]

53. Balakrishnan, M.; Sacia, E.R.; Bell, A.T. Syntheses of Biodiesel Precursors: Sulfonic Acid Catalysts for Condensation of Biomass-Derived Platform Molecules. ChemSusChem 2014, 7, 1078-1085. [CrossRef] [PubMed]

54. Bond, J.Q.; Alonso, D.M.; Wang, D.; West, R.M.; Dumesic, J.A. Integrated Catalytic Conversion of $\gamma$-Valerolactone to Liquid Alkenes for Transportation Fuels. Science 2010, 327, 1110-1114. [CrossRef]

55. Gruter, G.J.M.; Dautzenberg, F. Method for the Synthesis of 5-Alkoxymethylfurfural Ethers and Their Use. EP 20071834950 A1; Furanix Technologies BV [NL], 19 September 2007.

56. Gruter, G.-J.; de Jong, E. Furanics: Novel fuel options from carbohydrates. Biofuels Technol. 2009, 1, 11-17.

57. Lange, J.-P.; van der Heide, E.; van Buijtenen, J.; Price, R. Furfural-A Promising Platform for Lignocellulosic Biofuels. ChemSusChem 2012, 5, 150-166. [CrossRef]

58. Mascal, M.; Nikitin, E.B. Direct, High-yield conversion of cellulose into Biofuel. Angew. Chem. Int. Ed. 2008, 47, 7924-7926. [CrossRef] [PubMed]

59. Mascal, M.; Nikitin, E.B. Towards the efficient, total glycan utilization of biomass. ChemSusChem 2009, 2, 423-426. [CrossRef] [PubMed]

60. Lanzafame, P.; Temi, D.M.; Perathoner, S.; Centi, G.; Macario, A.; Aloise, A.; Giordano, G. Etherification of 5-hydroxymethyl-2-furfural (HMF) with ethanol to biodiesel components using mesoporous solid acid catalysts. Catal. Today 2011, 175, 435-441. [CrossRef]

61. Balakrishnan, M.; Sacia, E.R.; Bell, A. Etherification and reductive etherification of 5-(hydroxymethyl)furfural: 5-(alkoxymethyl)furfurals and 2,5-bis(alkoxymethyl)furans as potential biodiesel candidates. Green Chem. 2012, 14, 1626-1634. [CrossRef]

62. Johnson, W.S.; Werthemann, L.; Bartlett, W.R.; Brockson, T.J.; Li, T.; Faulkner, D.J.; Petersen, M.R. Simple Stereoselective Version of the Claisen Rearrangement Leading to trans-Trisubstituted Olefinic Bonds. Synthesis of Squalene. J. Am. Chem. Soc. 1970, 92, 741. [CrossRef]

63. Sampath Kumar, H.M.; Joyasawal, S.; Reddy, B.V.S.; Chakravarthy, P.; Krishna, A.D.; Yadav, J.S. Reaction of orthoesters with alcohols in the presence of acidic catalysts: A study. Indian J. Chem. 2005, 44B, 1686-1692.

64. Chaffey, D.R.; Davies, T.E.; Taylor, S.H.; Graham, A.E. Etherification Reactions of Furfuryl Alcohol in the Presence of Orthoesters and Ketals: Application to the Synthesis of Furfuryl Ether. ACS Sustain. Chem. Eng. 2018, 6, 4996-5002. [CrossRef]

65. Li, X.-L.; Zhang, K.; Chen, A.-Y.; Li, C.; Li, F.; Xu, H.-J.; Fu, Y. A cobalt catalyst for reductive etherification of 5-hydroxymethyl-furfural to 2,5-bis(methoxymethyl)furan under mild conditions. Green Chem. 2018, 20, 1095-1105. [CrossRef]

66. Pizzi, R.; van Putten, R.-J.; Brust, H.; Perathoner, S.; Centi, G.; van der Waal, J.C. High—Throughput Screening of Heterogeneous Catalysts for the Conversion of Furfural to Bio-Based Fuel Components. Catalysts 2015, 5, 2244-2257. [CrossRef]

67. Bethmont, V.; Montassier, C.; Marecot, P. Ether synthesis from alcohol and aldehydes in the presence of hydrogen and palladium deposited on charcoal. J. Mol. Catal. A 2000, 152, 133-140. [CrossRef]

68. Wang, Y.; Cui, Q.; Guan, Y.; Wu, P. Facile synthesis of furfuryl ethyl ether in high yield via reductive etherification of furfurol in ethanol over Pd/C under mild conditions. Green Chem. 2018, 20, 2110-2117. [CrossRef]

69. Li, C.; Xu, G.; Liu, X.; Zhang, Y.; Fu, Y. Hydrogenation of biomass-derived furfurol to tetrahydrofurfuryl alcohol over hydroxyapatite-supported Pd catalyst under mild conditions. Ind. Eng. Chem. Res. 2017, 56, 8843-8849. [CrossRef] 
70. Boronat, R.M.; Corma, A.; Renz, M. Mechanism of the Meerwein-Ponndorf-Verley-Oppenauer (MPVO) Redox Equilibrium on Sn- and Zr-Beta Zeolite Catalysts. J. Phys. Chem. B 2006, 110, 21168-21174. [CrossRef]

71. Corma, A.; Domine, M.E.; Valencia, S. Water-resistant solid Lewis acid catalysts: Meerwein-Ponndorf-Verley and Oppenauer reactions catalyzed by tin-beta zeolite. J. Catal. 2003, 215, 294-304. [CrossRef]

72. Corma, A.; Renz, M. A General Method for the Preparation of Ethers Using Water-Resistant Solid Lewis Acids. Angew. Chem. Int. Ed. 2007, 46, 298-300. [CrossRef]

73. Jae, J.; Mahmoud, E.; Lobo, R.F.; Vlachos, D.G. Cascade of liquid-phase catalytic transfer hydrogenation and etherification of 5-hydroxymethylfurfural to potential biodiesel components over Lewis acid zeolites. Chem CatChem 2014, 6, 508-513. [CrossRef]

74. Luo, J.; Yu, J.; Gorte, R.J.; Mahmoud, E.; Vlachos, D.G.; Smith, M.A. The effect of oxide acidity on HMF etherification. Catal. Sci. Technol. 2014, 4, 3074-3081. [CrossRef]

75. Iglesias, J.; Melero, J.A.; Morales, G.; Moreno, J.; Segura, Y.; Paniagua, M.; Cambra, A.; Hernandez, B. Zr-SBA-15 Lewis Acid Calayst: Activity in Meerwein Ponndorf Verley Reduction. Catalysts 2015, 5, 1911-1927. [CrossRef]

76. Nguyen, H.; Xiao, N.; Daniels, S.; Marcella, N.; Timoshenko, J.; Frenkel, A.; Vlachos, D.G. Role of Lewis and Bronsted acidity in metal chloride catalysis in organic media: Reductive etherification of furanics. ACS Catal. 2017, 7, 7363-7370. [CrossRef]

77. Shinde, S.; Rode, C. Cascade reductive etherification of bioderived aldehydes over Zr-based catalyst. ChemSusChem 2017, 10, 4090-4101. [CrossRef] [PubMed]

78. Scotti, N.; Zaccheria, F.; Bisio, C.; Vittoni, C.; Ravasio, N. Switching Selectivity in the Hydrogen Transfer Reduction. ChemistrySelect 2018, 3, 8344-8348. [CrossRef]

79. Scotti, N.; Dangate, M.; Gervasini, A.; Evangelisti, C.; Ravasio, N.; Zaccheria, F. Unraveling the Role of Low Coordination Sites in a Cu Metal Nanoparticle: A Step toward the Selective Synthesis of Second Generation Biofuels. ACS Catal. 2014, 4, 2818-2826. [CrossRef]

80. Zaccheria, F.; Psaro, R.; Ravasio, N. Bifunctional copper catalysts for an atom efficient ether synthesis. Tetrahedron Lett. 2009, 50, 5221-5224. [CrossRef]

81. Shinde, S.D.; Meng, X.; Kumar, R.; Ragauskas, A.J. Recent advances in understanding the pseudolignin formation in a lignocellulosic biorefinery. Green Chem. 2018, 20, 2192-2205. [CrossRef]

82. Hu, X.; Westerhof, R.J.M.; Wu, L.; Dong, D.; Li, C.-Z. Upgrading biomass-derived furans via acid-catalysis/hydrogenation: The remarkable difference between water and methanol as the solvent. Green Chem. 2015, 17, 219-224. [CrossRef]

83. Barbera, K.; Lanzafame, P.; Pistone, A.; Millesi, S.; Malandrino, G.; Gulino, A.; Perathoner, S.; Centi, G. The role of oxide location in HMF etherification with ethanol over sulfated $\mathrm{ZrO}_{2}$ supported on SBA-15. J. Catal. 2015, 323, 19-32. [CrossRef]

84. Bai, Y.; Wei, L.; Yang, M.; Chen, H.; Holdren, S.; Zhu, G.; Tran, D.T.; Yao, C.; Sun, R.; Pan, Y.; et al. Three-step cascade over a single catalyst: Synthesis of 5-(ethoxymethyl)furfural from glucose over a hierarchical lamellar multi-functional zeolite catalyst. J. Mater. Chem. A 2018, 6, 7693-7705. [CrossRef]

85. Xiang, B.; Wang, Y.; Qi, T.; Yang, H.-Q.; Hu, C.-W. Promotion catalytic role on Bronsted acid for the sequential dehydration-etherification of fructose to 5-ethoxymethylfurfural. J. Catal. 2017, 352, 586-598. [CrossRef]

86. Zaccheria, F.; Scotti, N.; Ravasio, N. The Role of Copper in the Upgrading of Bioalcohols. ChemCatChem 2018, 10, 1526-1535. [CrossRef]

87. Seemala, B.; Kumar, R.; Cai, C.M.; Wyman, C.E.; Christopher, P. Single-step catalytic conversion of furfural to 2-pentanol over bimetallic Co-Cu catalysts. React. Chem. Eng. 2019, 4, 261-267. [CrossRef]

(C) 2019 by the authors. Licensee MDPI, Basel, Switzerland. This article is an open access article distributed under the terms and conditions of the Creative Commons Attribution (CC BY) license (http://creativecommons.org/licenses/by/4.0/). 